DE91 013613

\title{
RF IMPEDANCE MEASUREMENTS OE THE VARIOUS VACUUM CHAMBERS FOR THE ADVANCED PHOTON SOURCE (APS)*
}

\author{
J.J.Song, J.W.Howell, R.L.Kustom, and J.E.Bridges \\ Argonne National Iaboratory, Argonne, IL 60439
}

ABSTRACT

Coupling impedanoes (z) for the 7-GeV APS storage ring have been numerically estimated [1]. In order to confirm these calculations, measurements of the coupling impedance of various vacuum components around the main storage ring was done with a synthetic pulse technique. A section of the beam + ante-chamber, a vacuum valve with and without the intemal RF screen, and a photon absomber were used as a device under test (DUT) to obtain the preliminary results. The result in the frequency domain (FD) measurement was compared with previous time domain (TD) measurement and with the corputer simulation of the APS impedance budget. [2]. The $\mathrm{z}$ or $\mathrm{k}$ deperdance on the pulse length and the thickness of the center wire was examined.

\section{INIRODUCTION}

The coupling inpedance must be kept small so that the desired operating current is achieved. A ccrnoutational investigation has been carried out to estimate the coupling imoecianoe of a large vaziety of structures in the ADS ring. This was done mainly by w.Chou [2], using the 2D, 3D MAFIA codes and TBCI code. The results are summarized in Table 1 as the APS impeciance budget. As seen, the largest longitudinal impedance is contributed by the RE cavities (even thougin the contribution of the fiundamental mode has been subtracted from the calculation) and the transverse impedance is mainly contributed by the transitions between the beam chariber and the insertion device (II) section. The longitudinal inpedance and the transverse impedance are estimated to be $1 \Omega$ and 0.15 $\mathrm{M} \Omega / \mathrm{m}$, respectively.

The coupling inpedance of the APS vacunm chanr ber components masured with a coaxial wire method, using a synthetic pulse technique [3]. The measurements were done on a section of the beamand ante-ciamber, and a vacum valve with and without the internal RE. screen. A photon absorber is presently under test. The measurements will assist in the design of the various components of the storage ring, especially the type of the RF screen that will be used near the photon absorber.

*Work supported by U.S.Department of Energy, Office of Basic Sciences, under Contract W-31-109ENG 38 .
For a given bean bunch witin charge, $q$, the energy loss of the bunch is

$$
\Delta E=k q^{2}=2 z_{c q^{2}} \frac{\int I_{1}\left(I_{1}-I_{2}\right) \text { dt }}{\left(I_{I_{1}} \text { it) }\right)^{2}}(\mathrm{eV}) \text {, }
$$

where $z_{0}$ is the characteristic impedance of the coaxial wire, $I_{1}$ is the current flowing through the reference chamber, and $I_{2}$ is the cursent flowing through the DUT (see Fig.1). Thus the longitudinal loss parameter can be rreasured by the integration of the current, which is also a function of the beam bunch length, $\sigma$. The courling impedance, $\mathrm{Z}$, can be derived from the wake potential of a beam bunch,

$$
W_{b}(t)=-\frac{2 z_{0}\left[I_{1}-I_{2}\right]}{q} \quad(v / p C) .
$$

Transforming eq. (2) into the FD gives the longitudinal impedance as;

$$
Z(\omega)=2 \mathrm{Z}_{0} \frac{\left[I_{2}(\omega)-I_{2}(\omega)\right]}{I_{i}(\omega)} \quad(\Omega)
$$

\section{EXPERTMENTAL SETUP}

As depicted in Fig.1, a Network Analyzer (HIP8510B) was used to measure the two-port S-parameters of the DUT. The frequency span is varied from $45 \mathrm{MHz}$ to $18 \mathrm{GHz}$, depending on the appropriate symthetic pulse length, $\sigma$. An $\mathrm{HP} 9000 / 308^{\circ} \mathrm{com}-$ puter was used for data acquisition and the control of the system. The tire damain option canputes a synthetic pulse via the Fast InverseFourier Transform (EFT) from the FD data. The terperature in the roan was $74 \pm 2$ F to get a reliable signal from the DUT.

The test systen consists of a piece of the APS beam chamber (50 cm long), the DUT (10 cm) and the transition portions ( $30 \mathrm{~cm}$ each). The transition portion is tapered at $10^{\circ}$ to eliminate multiple reflections due to sharp discontinuities. The parameters in the test systen and in the APS storage ring are sumarized in Table 2. Three different types of center conductors were used: a 2 mm-brass wire, a $9.5 \mathrm{~mm}-\mathrm{cu}$ pipe, and an elliptical $50 \Omega-$ matcining Al rod.

In the impedance computation, the use of the transmission coefficient $\left(S_{21}\right)$ instead of the reflection coefficient $\left(S_{11}\right.$ ) renuces the error in $Z(\omega)$ because the multiple reflections must be con-

sidered for the $s_{11}$ :
OISTRibUTION of THIS DeCumENT is Uinlimite 


\section{DISCLAIMER}

This report was prepared as an account of work sponsored by an agency of the United States Government. Neither the United States Government nor any agency thereof, nor any of their employees, makes any warranty, express or implied, or assumes any legal liability or responsibility for the accuracy, completeness, or usefulness of any information, apparatus, product, or process disclosed, or represents that its use would not infringe privately owned rights. Reference herein to any specific commercial product, process, or service by trade name, trademark, manufacturer, or otherwise does not necessarily constitute or imply its endorsement, recommendation, or favoring by the United States Government or any agency thereof. The views and opinions of authors expressed herein do not necessarily state or reflect those of the United States Government or any agency thereof. 
TABLE 1 APS impedance budget.

\begin{tabular}{|c|c|c|c|c|}
\hline \multirow{2}{*}{\multicolumn{2}{|c|}{ Component }} & \multirow[t]{2}{*}{ Number } & \multicolumn{2}{|c|}{ Impeosices } \\
\hline & & & (ni) & $\mathrm{Zl}$ \\
\hline & AF Cavity (HOM) & 15 & 0.2 & 0.02 \\
\hline & $\begin{array}{l}\text { Transition beiween chamber a } \\
\text { ID saclion }\end{array}$ & 34 & 0.03 & 0.06 \\
\hline & $\begin{array}{l}\text { Transillon beneen chiamber \& } \\
\text { it section }\end{array}$ & 3 & 0.1 & 0.003 \\
\hline & Croleh absorber & 160 & 0.01 & 0.002 \\
\hline & Shialdad bellows & 160 & 0.04 & 0.007 \\
\hline & Shieided Vransilions & 80 & 0.02 & 0.003 \\
\hline & Fang & 480 & 0.01 & 0.008 \\
\hline & Elliptical lube woldment & 80 & IE-3 & $1 E-3$ \\
\hline & Shielded and contlat & 80 & $1 E \cdot 3$ & $1 E-3$ \\
\hline 10. & Vaive & 80 & 0.01 & 0.01 \\
\hline 19. & Beam position manilar & 360 & 0.02 & \\
\hline & $\begin{array}{l}\text { Transition benween citamber } \\
\text { w. \&.w/o ante chamber }\end{array}$ & 120 & 3E-3 & 1E.3 \\
\hline & Resistive wall & & 0.01 & 0.01 \\
\hline & Spaca.charge & & 1E.5 & 0.03 \\
\hline \multirow{2}{*}{\multicolumn{3}{|c|}{$\begin{array}{l}\text { 15. Olhars } \\
\text { (kjekars, bumpers, ion pump ports, alc) }\end{array}$}} & 0.3. & \\
\hline & & & & \\
\hline & atotal & & 1 & 0.15 \\
\hline & Jggl (subtotal X 2) & & $2 \Omega$ & $0.3 \mathrm{M} / \mathrm{m}$ \\
\hline
\end{tabular}

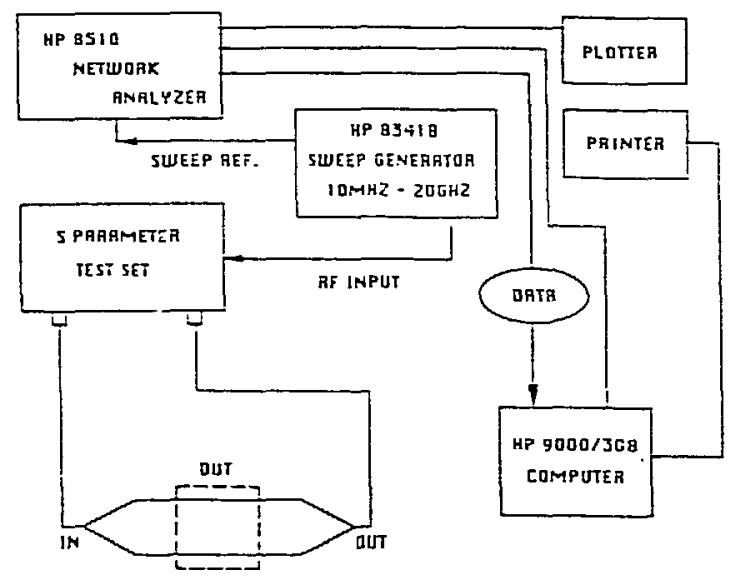

Eig.1 Experimental setup.

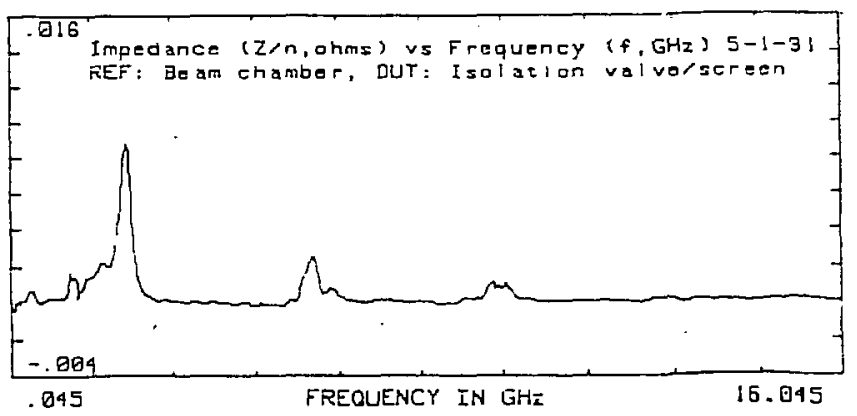

Fig.2 The normalized inpedance, $\mathrm{Z}(\omega) / \mathrm{n}$, of the isolation valve with the $R F$ screen.

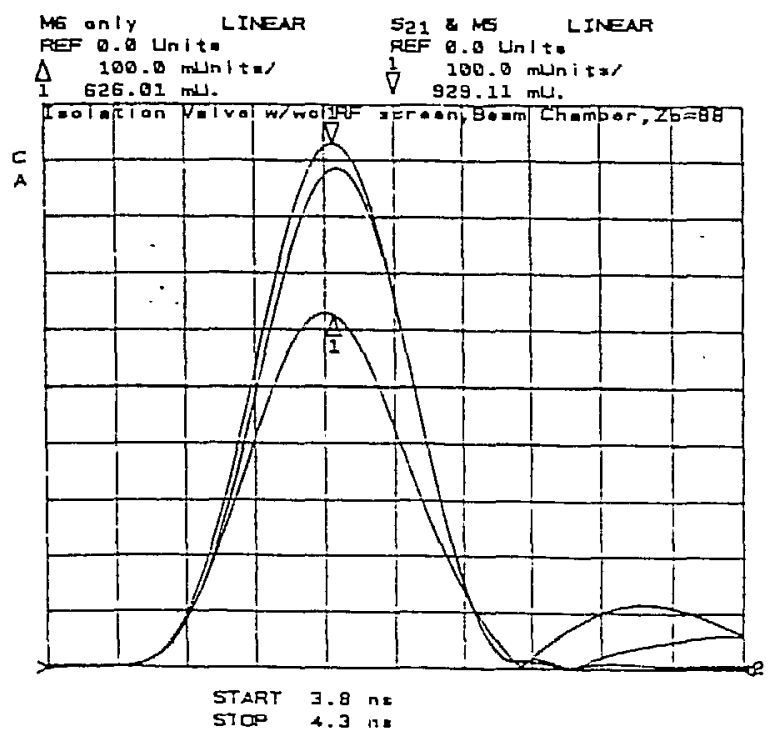

Fig.3 The TD transion of the S21 of DUT: the top curve is the reference chamber, the middle is the RE-screened valve, the bottem is the regular valve.

\begin{tabular}{|c|c|c|c|c|}
\hline Frequency $(\mathrm{GH} z)$ & $\underline{0.16}$ & $\underline{0-10}$ & $\underline{0.5}$ & $\underline{2-5}$ \\
\hline Bunch Lenath $(\sigma: \mathrm{cm})$ & 12 & $\underline{1.8}$ & $\underline{5.8}$ & $\underline{9.6}$ \\
\hline Bunch Length ( $\sigma:$ DS $)$ & 37.5 & 60 & 192 & 32 \\
\hline K (Valve w AF) & $\underline{0.023}$ & & $\underline{0.014}$ & 0.008 \\
\hline KiValve wo RF & 0.123 & $\underline{0.059}$ & $\underline{0.042}$ & $\underline{0.039}$ \\
\hline$K$ (Ante-chamber) & 0.002 & & 0.001 & \\
\hline Error in $\mathrm{K}$ & $\underline{6 E-04}$ & & $3 E-04$ & \\
\hline
\end{tabular}

Table 3. Ioss parameters of the various DUTs in different frequency spans.

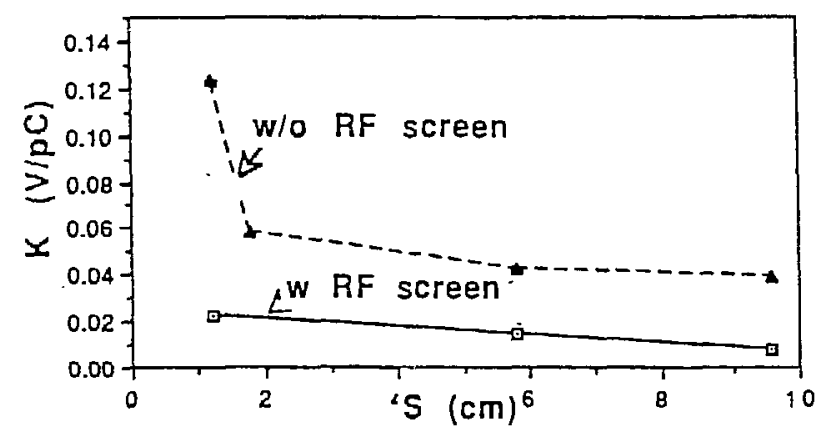

Fig.4 The loss parameter of the isolation valve, $k$, vs the bunch length, $\sigma$. 
Table 2. Test system and APS storage ring parameters

Characteristic impedance

of the center conductor, $z_{0}=125,88,50 \Omega$

Swep frequency, $\Delta f=45 \mathrm{MHz}-18 \mathrm{GHz}$

Nominal energy, $\quad \mathrm{E}=7.0 \mathrm{GeV}$

Revolution Frequency, $\quad f_{0}=271.55 \mathrm{kHz}$

Beam chamber-cutoff freq. $f_{\text {cut }}=4.6 \mathrm{GHz}$

Bunch length, ans $\sigma_{\text {tns }}=\quad 5.3 \mathrm{~mm}$

Bunch length, EWHM $\sigma=27.5 \mathrm{ps}$

Number of bunch, $\quad \mathrm{m}_{\mathrm{D}}=20$

Bunch curcent. _._. I I $=4 \mathrm{~mA}$

$$
z(\omega)=2 z_{0} \frac{\left[S_{21} \text { (ref) }-S_{21} \text { (DUT) }\right]}{S_{21}(\text { ref })} \quad(\Omega) .
$$

In order to convert the data into the beamimpedance for a single bunch, the impedance, is nomalized:

$$
\underline{z}=\frac{z(\omega)}{\Omega}
$$

where $n=\omega / 2 \pi f_{0}$ and $f_{0}$ is the revolution freouency of a beam in a storage ring. The total impedance can be obtained by multiplying $k$ by the passage time between bunches in a storage ring, or

$$
z_{t a c}=\frac{k}{n_{0} f_{0}} \quad(\Omega) \text {, }
$$

where $n_{0}$ is the number of bunches in a storage ring.

\section{MEASUREMENTS AND RESUITS}

The small section of the beam and ante-chamber was measured to compare with the previous experiment in the TD [4]. Even though the error of $k$ is as high as $30 \%$, the resolution is much irtoroved. The ID measurement for the smail $k$-values was repeatable only unto $0.002 \mathrm{~V} / \mathrm{pC}$ because of the amplitude jitter in the real-time pulse [4]. In the FD measurement, the repeatability error was $6 x$ $10^{-4} \mathrm{~V} / \mathrm{pC}$ in the $0-16 \mathrm{GHz}$ span and the k-value was measured to be $2 \times 10^{-3} \mathrm{~V} / \mathrm{pC}$ (see Table 3).

For the large value of the $k$, There are no sig nificant effects of the size of the center conductor. For the small $k$, the thickest center piece apparently gives more transmission rate $\left(S_{21}\right)$, because it gives the exact $50 \Omega$ matching in the DUT.

The typical result of the longitudinal impedance for the vacum valve with the RF screen is plotted in Fig.2, using the eong (4) and (5). Some resonant peaks at $2.3,5.9$, and $9.4 \mathrm{GHz}$ are observed, but the $Q$ values are low $(\leq 20)$ so that the contribution to the overall impedance is small. The cause of these are not specifically known, but several poseible candidates are abvious and they will be investigated.
The result transfonned into the To is shown in Fig.3, including the S21 for the valve with no RF screen. The top curve is for the reference chamber, the midalle curve is the valve with the $\mathrm{RF}$ screen, and the bottan curve is without the RF screen.

Fig. 4 shows the relation of $k$ and $\sigma$ (the bunch length). The bunch length is varied by changing the frequency span over which the data is recorded. The loss parameter (k) is higher for the shorter bunch and much larger for the valve w/o the RF screen. Table 3 summarizes all the loss parameter measurements.

\section{CONCLUSION AND NEAR FUTURE PLAN}

Several general conclusions can be made: -The RF-screened valve has a factor of five imr provement over a standard valve and the previous ID measurements with the real-time pulse were correct, but had too a low resolution for the small$\mathrm{k}$.

-Further measurements will be done on the photon absorber, the 352-MHz cavity, the ingertion device, the transition section between various size vacurm pipes.

-It is also planed to determine the type of the RF screen on the photon absorber. the experiment on the aperture coupling is under way and the can puter simulation was done [5].

\section{ACKNOWLEDGEMENTS}

The authors would like to thank Dr.F.Caspers at CERN for stimulating discussions. Also thanks must be given to D.F.Voss, T.Smith, J.Bulmahn, B.Stephenson, and E. Wallace for their technical support.

\section{REFERENCES}

[1] L.C.Terg, "Irpedance and Current Limitations, DOE Review of APS Project at Argonne Nat'l Lab., March 6-8,1990.

[2] W.Chou, Y.Jin, "Impedance Studies-Part 4: The APS Impedance Budget", ANL-LS-115, 1988;

"Impedance and Bunch Iengthening in the APS," in Proc. of the Impedanoe and Bunch Instability Workshop, (1950)

[3] F.Caspers, "Beam Imoedance Measurement By the Wire Method using a Synthetic Pulse Technique," IEEE-Trans. on Nuclear Science, V NS-32, 1914 (1985) .

[4] R.L.Kustom, et.al, "RF Impedance Studies of a Beam Chamber and Iongitudinally Slot-Coupled Vacurum Pumping Antechamber," IFEE Particle Accelerator Conf., 1304 (1987).

[5] Y.Chae and I.C.Teng, "Study of Ioss Factor for slots in the vacum Chamber," in this proceedings. 